\title{
Nrf2 represses the onset of type 1 diabetes in non-obese diabetic mice
}

\author{
Yoko Yagishita1,2, Akira Uruno1,3, Dionysios V Chartoumpekis², Thomas W Kensler2 and Masayuki Yamamoto1,3 \\ 1Department of Medical Biochemistry, Tohoku University Graduate School of Medicine, Sendai, Miyagi, Japan \\ 2Department of Pharmacology and Chemical Biology, School of Medicine, University of Pittsburgh, Pittsburgh, Pennsylvania, USA \\ ${ }^{3}$ Tohoku Medical-Megabank Organization, Tohoku University, Sendai, Miyagi, Japan
}

Correspondence should be addressed to M Yamamoto or A Uruno: masiyamamoto@med.tohoku.ac.jp or uruno@med.tohoku.ac.jp

\begin{abstract}
The transcription factor Nrf2 (NF-E2-related factor 2) plays a critical role in oxidative stress responses. Although activation of Nrf2 signaling is known to exert antiinflammatory effects, the function of Nrf2 in inflammation-mediated autoimmune disorders, such as type 1 diabetes, is not well established. To address the roles of Nrf2 in protection against autoreactive T-cell-induced type 1 diabetes, we used non-obese diabetic (NOD) mice, which are a polygenic model of human type 1 diabetes, to generate a genetic model for assessment of the contribution of Nrf2 activation to prevention and/or treatment of type 1 diabetes. Because Keap1 (Kelch-like ECH-associated protein 1) negatively regulates Nrf2, we used Keap1 gene knockdown driven by either hypomorphic or knockout Keap1 alleles, which enhanced Nrf2 signaling to moderate or excess levels, respectively. Nrf2 activation in the NOD::Keap1FA/- mice inhibited T-cell infiltration within or near the islets, ameliorated impairment of insulin secretion and prevented the development of diabetes mellitus. Notably, Nrf2 activation decreased both the plasma interferon- $\gamma$ (IFN- $\gamma$ ) levels and the IFN- $\gamma$-positive cell numbers in the pancreatic islets. The amelioration of diabetes was also observed in the NOD mice with two hypomorphic Keap1 alleles (Keap1FA/FA) by intermediate activation of Nrf2. Both NOD::Keap1FA/- and NOD::Keap1FAFA mice had a decreased incidence of diabetes mellitus, demonstrating that activation of Nrf2 signaling prevented the onset of type 1 diabetes mellitus in NOD mice. Thus, Nrf2 appears to be a potential target for the prevention and treatment of type 1 diabetes.
\end{abstract}
Key Words
- Nrf2
- NOD mice
type 1 diabetes
- insulitis

\section{Introduction}

Type 1 diabetes is caused by destruction or dysfunction of insulin-producing pancreatic $\beta$-cells, and its incidence is increasing in the modern world (Tuomilehto 2013). Protecting $\beta$-cells from inflammation and destruction is an attractive means of preventing and/or treating type 1 diabetes. Identifying novel targets that protect $\beta$-cells from damage related to type 1 diabetes is an important goal, and searches for such targets have been widely conducted.
The transcription factor Nrf2 (NF-E2-related factor 2) plays a critical role in cellular responses to oxidative and electrophilic stresses (Itoh et al. 1995). In quiescent conditions, Keap1 (Kelch-like ECH-associated protein 1) suppresses Nrf2 activity by serving as a scaffold and substrate recognition subunit for the Cul3 ubiquitin ligase machinery, which marks Nrf2 for rapid degradation through the ubiquitin-proteasome pathway. 
Upon exposure to environmental or inflammatory stresses, Keap1 cysteine residues are modified, which dampens Nrf2 degradation. Nrf2 accumulates in the nucleus and induces target gene expression (Itoh et al. 1997, 1999). The Keap1-Nrf2 signaling pathway acts as a key regulator of protective responses against oxidative and inflammatory stresses (Kensler et al. 2007, Taguchi et al. 2011, Uruno \& Motohashi 2011, Yamamoto et al. 2018).

Nrf2 deficiency has been reported to aggravate inflammation in mice (Itoh et al. 2004, Khor et al. 2006, Thimmulappa et al. 2006). Conversely, Nrf2 activation exerts anti-inflammatory effects in many rodent models of inflammation (Kobayashi et al. 2016). The mechanisms underlying Nrf2-mediated protection against inflammation reflect induction of anti-oxidative responses in many cell types as well as suppression of transcriptional upregulation of pro-inflammatory cytokine genes in macrophages (Kobayashi et al. 2016). Nrf2 signaling also suppresses inflammation provoked by autoimmune disorders in Scurfy mice, which possess a missense mutation in the Foxp3 gene (Suzuki et al. 2017). The activation of Nrf2 signaling also inhibits experimental autoimmune encephalomyelitis in mice (Hayashi et al. 2015). Importantly, the Nrf2 inducer dimethyl fumarate is in clinical use for the treatment of multiple sclerosis in humans (Fox et al. 2012). However, little is known about the impact of Nrf2 on inflammation in type 1 diabetes.

Nrf2 has been shown to modify the pathogenesis of metabolic disorders (Chartoumpekis \& Kensler 2013, Uruno et al. 2015), and induction of Nrf2 signaling protects against type 2 diabetes in rodents (Zhang et al. 2010, Uruno et al. 2013, 2016, Slocum et al. 2016, Yagishita et al. 2017) and humans (Axelsson et al. 2017). The protective effects of Nrf2 have also been studied in a streptozotocin (STZ)-induced mouse model of type 1 diabetes (Song et al. 2009, Zheng et al. 2011, Cui et al. 2012). Pancreatic $\beta$-cell damage and consequent diabetic nephropathy are partially prevented by treatment with Nrf2 inducers, such as sulforaphane. Although the STZinduced diabetic model develops insulitis, $\beta$-cell damage is induced primarily due to the chemical toxicity of STZ in these cells, and thus, the damage does not reflect immune system dysregulation (Van Belle et al. 2009). Therefore, studies utilizing alternative models to address the roles of Nrf2 signaling in autoimmune-based diabetes are needed.

Non-obese diabetic (NOD) mice have been used widely as a polygenic model of human type 1 diabetes (Makino et al. 1980). These mice develop diabetes spontaneously between 12 and 30 weeks of age and have features of inflammation of pancreatic islets, apoptosis of insulin-producing $\beta$-cells, hyperglycemia, polyuria and weight loss (Anderson \& Bluestone 2005).

To determine whether and how Nrf2 contributes to the prevention and/or treatment of type 1 diabetes, we generated genetic models with activation of Nrf2 signaling in the NOD background. Specifically, we used mice harboring a hypomorphic allele of Keap1 (Keap1 $1^{\text {floxA }}$ and Keap1 ${ }^{F A}$ ) (Okawa et al. 2006, Taguchi et al. 2010, Uruno et al. 2016) in combination with a Keap1-knockout allele (Wakabayashi et al. 2003) to generate Keap $1^{\mathrm{FA} /-}$ and Keap $1^{\text {FA/FA }}$ mice. Severe and moderate Keap1 gene knockdown in the Keap $1^{F A /-}$ and Keap $1^{F A / F A}$ mice, respectively, caused strong and moderate Nrf2 stabilization and enhanced downstream signaling. The results unequivocally show that the activation of Nrf2 signaling plays an important role in defining susceptibility to autoimmune diabetes through anti-inflammatory effects.

\section{Materials and methods}

\section{Mice}

Keap $1^{\text {FA/+ }}$ (Okawa et al. 2006) and Keap1+/- (Wakabayashi et al. 2003) mice were backcrossed with NOD/Shi (CLEA Japan) mice for at least eight generations. NOD/Shi background Keap1 $1^{F A /-}$ and Keap1 $1^{F A /+}$ control mice were generated from NOD/Shi background Keap $1^{\text {FA/FA }}$ and Keap1 $1^{+/}$mating pairs. NOD/Shi background Keap1 $1^{\text {FA/FA }}$ and Keap1 ${ }^{+/+}$mice were generated from NOD/Shi background Keap $1^{F A /+}$ mating pairs. All the animal experiments were approved by the Animal Committee at Tohoku University. All mice used in this study were female. Mice with blood glucose levels $>250 \mathrm{mg} / \mathrm{dL}$ in consecutive measurements performed at 14-day intervals were considered diabetic.

\section{Blood glucose and plasma insulin, glucagon, $\beta$-hydroxybutyrate and interferon- $\gamma$ level measurements}

The blood glucose concentrations were determined with the OneTouch Ultra blood glucose analyzer (LifeScan, Milpitas, CA, USA). The plasma insulin, glucagon and $\beta$-hydroxybutyrate concentrations were measured using a mouse insulin ELISA kit (Mercodia, Uppsala, Sweden), a glucagon ELISA kit (Mercodia) and a $\beta$-hydroxybutyrate colorimetric assay kit (Cayman), respectively, according to the manufacturers' instructions. The plasma interferon- $\gamma$ $($ IFN- $\gamma$ ) levels were determined with a Luminex fluorescent 
bead array system using a Mouse High Sensitivity Kit 2plex (Millipore). The minimum detectable concentration of IFN- $\gamma$ was $0.15 \mathrm{pg} / \mathrm{mL}$.

\section{Histological analyses}

Pancreata were immersed in 4\% paraformaldehyde or Mildform 10N (Wako Pure Chemicals), and hematoxylin and eosin (H\&E)-stained sections were prepared. Immunohistochemistry was performed using goat polyclonal anti-NQO1 (1:500, ab2346, Abcam), rat monoclonal anti-Foxp3 (1:50, clone FJK-16s, eBioscience, San Diego, CA, USA) and rabbit polyclonal anti-IFN- $\gamma$ (1:200, ab9657, Abcam) antibodies. Pancreatic sections stained with H\&E were scored for insulitis using five grades according to the extent of mononuclear cell infiltration into the pancreatic islets as follows: grade 0 , no infiltration; grade 1, predominantly peri-islet mononuclear cell infiltration; grade 2 , infiltration in $25-50 \%$ of the islets; grade 3 , infiltration in $50-75 \%$ of the islets and grade 4 , infiltration in $>75 \%$ of the islets. Nine to eighteen islets in each pancreas from 5 to 10 mice were examined. The overall incidence and degree of insulitis for each group were calculated. For fluorescent staining, pancreatic sections were stained with guinea pig polyclonal antiinsulin (1:100, ab7842, Abcam) and rabbit monoclonal anti-glucagon (1:100, clone EP3070, ab92517, Abcam) antibodies as previously described (Yagishita et al. 2014). All secondary antibodies conjugated to fluorescent dyes were used at a 1:200 dilution. Imaging was performed using a Leica DM5000B microscope and a Leica DFC300 FX camera, a Leica DM2500 LED microscope and a Leica MC170 HD camera or a ZEISS LSM510 META microscope. The quantification analyses for insulin and glucagon were performed using a digital scanning system (Aperio FL, Leica Biosystems) and the HALO Image Analysis module (Indica Labs, Corrales, NM, USA).

\section{Insulin and glucagon content analysis in tissue extracts}

Whole pancreata were dissected and weighed. The tissues were homogenized in acid-ethanol, and the homogenate was centrifuged. Insulin or glucagon was measured in the collected supernatant with an insulin ELISA kit (Morinaga, Tokyo, Japan) or a glucagon ELISA kit (Mercodia) following the manufacturers' instructions. The hormone content was normalized by the tissue weight.

\section{RNA preparation and qPCR}

Total RNA was extracted from the livers and spleens with the Isogen reagent (Nippon Gene) or SepasolRNA SuperG (Nakarai Tesque). Total RNA was subjected to reverse transcription (RT) using the PrimeScript RT master mix (TaKaRa Bio) or the qScript system (Quanta Biosciences). Thereafter, the obtained templates were used for quantitative real-time PCR with the KAPA SYBR FAST qPCR Master Mix (2×) Kit (Kapa Biosystems) and the QuantStudio 6 Flex Real-Time PCR System (Thermo Fisher Scientific) or the iQ SYBR Green Supermix (Bio-Rad) and the iCycler-MyIQ (Bio-Rad). The primer sequences are provided in Supplementary Table 1 (see section on supplementary data given at the end of this article).

\section{Statistical analysis}

All data are presented as the mean \pm standard error of the mean (s.E.M.). Statistical analyses were performed using Student's $t$-test, Mann-Whitney $U$ test and analysis of variance (ANOVA), followed by Fisher's least significant difference (LSD) post hoc test for multiple comparisons. Log-rank tests were performed for the Kaplan-Meier survival curves. SPSS 21.0 (IBM) and Prism 7 (GraphPad Software) were used for all analysis.

\section{Results}

\section{Generation of Nrf2-activated NOD mice}

To assess whether Nrf2 plays important protective roles against the development of type 1 diabetes, we generated a mouse model in which Nrf2 signaling was genetically activated in the NOD background. We generated NOD/Shi background Keap1 $1^{\text {FA/FA }}$ (NOD::Keap1 $\left.{ }^{F A / F A}\right), \quad K e a p 1^{F A /+}$ (NOD::Keap1 $1^{F A /+}$ ) and Keap1 $1^{+/+}\left(\mathrm{NOD}:\right.$ Keap1 $\left.{ }^{+/+}\right)$mice by intercrossing NOD::Keap1 $1^{F A /+}$ mice. The mating strategies used to generate these mice are shown in Fig. 1A. To confirm systemic Nrf2 activation in the NOD::Keap1 $1^{F A / F A}$ mice, first we examined the mRNA expression level of Nqo1, which is a prototypic Nrf2 target gene (Fig. 1B). Expression levels of Nqo1 transcripts in the spleen were comparable in the NOD::Keap1+/+ and NOD::Keap1 $1^{\text {FA/+ }}$ mice. In contrast, the Nqo1 transcript levels were increased approximately twofold in the NOD::Keap1 ${ }^{F A / F A}$ mice, which indicated Keap1 knockdown and the resulting induction of Nrf2 signaling in this mouse model. 

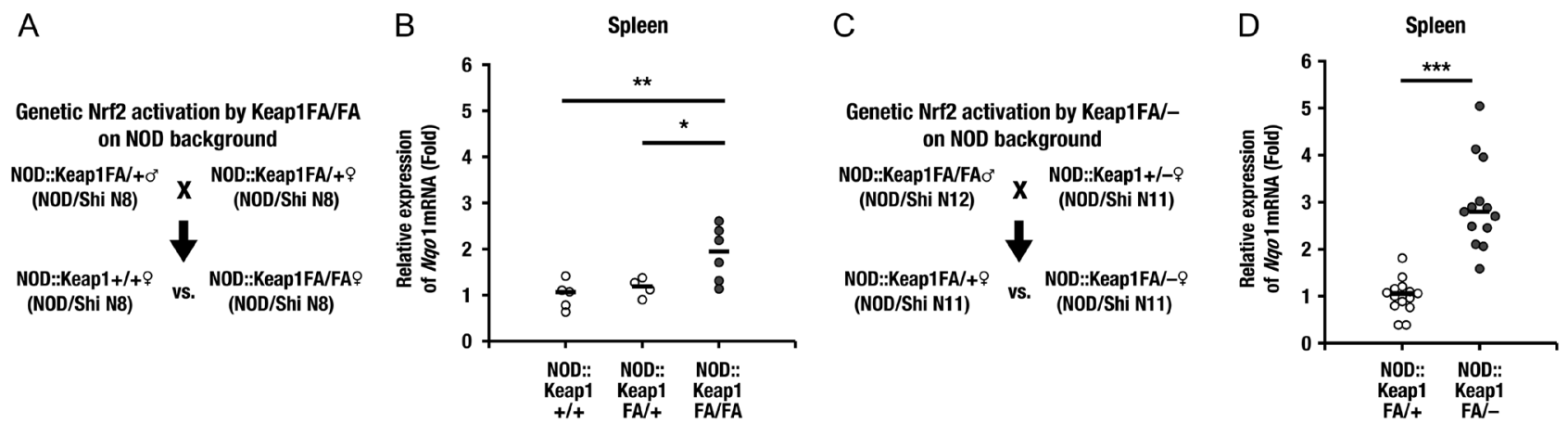

\section{Figure 1}

A mouse model of type 1 diabetes with concomitant activation of Nrf2 signaling activation. (A) Keap 1FA/+ mice were backcrossed with NOD/Shi background mice for eight generations (N8). The mice were mated to obtain NOD::Keap1+/+, NOD::Keap1FAl+ and NOD::Keap1FAFA genotype mice. The NOD::Keap $1^{+/+}$and NOD::Keap1FAFA mice were examined for eight successive generations (N8) as indicated. (B) Nqo1 mRNA expression levels in the spleens of the NOD::Keap $1^{+/+}(n=5), \mathrm{NOD}:: K e a p 1^{\text {FA+ }}(n=4)$ and NOD::Keap 1FAFA mice $(n=6)$. The data were normalized to $\beta$-actin, and the expression levels in the NOD::Keap1+/+ mice were set as 1. (C) The Keap1FAFA and Keap1+/- mice were backcrossed with NOD/Shi background mice for 12 and 11 generations (N12 and N11), respectively. The NOD::Keap 1FAFA mice and NOD::Keap 1+/- mice were mated, and NOD::Keap1FA/- and NOD::Keap $1^{\text {FA/+ }}$ mice were generated as indicated. (D) Nqo1 mRNA expression levels in the spleens of the NOD::Keap1FA/+ $(n=14)$ and NOD::Keap1FA- $(n=13)$ mice. The data were normalized to $\beta$-actin, and the expression levels in the NOD::Keap1FA+ mice were set as 1. The bar represents the median. ANOVA followed by Fisher's LSD post hoc test for (B) and Student's $t$-test for (D) were applied. ${ }^{*} P<0.05,{ }^{*} P<0.01$ and $* \star * P<0.001$.

Because Keap1 $1^{\text {FA/- }}$ mice were demonstrated to exhibit stronger activation of Nrf2 signaling than Keap1FA/FA mice (Taguchi et al. 2010), we also generated NOD/Shi background Keap1 $1^{\text {FA/ }}$ (NOD::Keap1 ${ }^{\text {FA/-) }}$ mice by crossing NOD::Keap $1^{\text {FA/FA }}$ mice with NOD::Keap1 $1^{+/}$mice (Fig. 1C). The NOD::Keap1 ${ }^{\text {FA/ }}$ and NOD::Keap1 $1^{\text {FA/FA }}$ mice were examined by comparing the Nqo1 mRNA expression levels in the spleen. As shown in Fig. 1D, the NOD::Keap1 1FA/ mice had approximately three-fold higher Nqo1 expression than the NOD::Keap1 $1^{F A /+}$ mice; this finding confirmed graded activation of Nrf2 signaling in a gene dosagedependent manner (Taguchi et al. 2010). Because the NOD::Keap $1^{\text {FA/+ }}$ and NOD::Keap1 ${ }^{+/+}$mice had comparable Nqo1 mRNA expression, we used the NOD::Keap1 ${ }^{F A /+}$ mice as a control in the experiments with NOD::Keap $1^{\text {FA/- }}$ mice in this study.

\section{Activation of Nrf2 signaling decreases the incidence of diabetes mellitus in NOD mice}

The lengths of time in which a small cohort of NOD::Keap1 ${ }^{\text {FA/ }}$ mice $(n=11)$ and NOD::Keap $1^{\text {FA/ }}$ mice $(n=7)$ remained diabetes free were analyzed with the Kaplan-Meier method (Kaplan \& Meier 1958). Blood glucose levels $>250 \mathrm{mg} / \mathrm{dL}$ were used to define mice that developed diabetes mellitus. Five of 7 (71\%) of the control NOD::Keap $1^{F A /+}$ mice developed diabetes between 16 and 24 weeks of age. In contrast to these mice, the NOD::Keap $1^{\text {FA/ }}$ mice showed a significant delay and reduction in the incidence of diabetes development, with 1 of 11 (9\%) of NOD::Keap1 $1^{\text {FA/ }}$ mice developing diabetes by 24 weeks of age (Fig. 2A).

We also examined the blood glucose levels and body weight changes. The blood glucose levels were significantly increased in the control NOD::Keap $1^{\text {FA/+ }}$ mice at 16 weeks of age, while the levels were consistently normal in the NOD::Keap $1^{F A /-}$ mice throughout the experimental period (Fig. 2B). The body weights of the NOD::Keap $1^{F A /+}$ mice increased until 12 weeks of age and then started to decrease after 16 weeks of age (Fig. 2C). Although weight loss is commonly observed in NOD mice (Makino et al. 1980) as shown in the NOD::Keap1 ${ }^{\text {FA/+ }}$ mice, the body weights of the NOD::Keap $1^{\text {FA/ }}$ mice gradually increased throughout the experimental period. A published report showed that the body weights of the WT background Keap $1^{\text {FA/- }}$ mice were lower than those of the control Keap $1^{F A /+}$ mice after 6 weeks of age and did not increase substantially thereafter (Uruno et al. 2013), which was confirmed in the NOD background Keap1 ${ }^{\mathrm{FA} / \text { - }}$ mice before 16 weeks of age. However, after 18 weeks of age, the NOD::Keap $1^{\text {FA/ }}$ mice showed higher body weights than the NOD::Keap $1^{F A /+}$ mice without disturbing the normal rate of body weight gain.

To determine how the activation of Nrf2 lowered the blood glucose levels, we measured plasma insulin levels in the NOD::Keap1 ${ }^{\text {FA/- }}$ mice at 24 weeks of age. The NOD::Keap $1^{\text {FA/- }}$ mice had higher plasma insulin levels than the control NOD::Keap1 ${ }^{F A /+}$ mice (Fig. 2D). Moreover, the blood glucose levels were inversely and sharply correlated with the plasma insulin levels in the NOD::Keap $1^{\text {FA/- }}$ and 

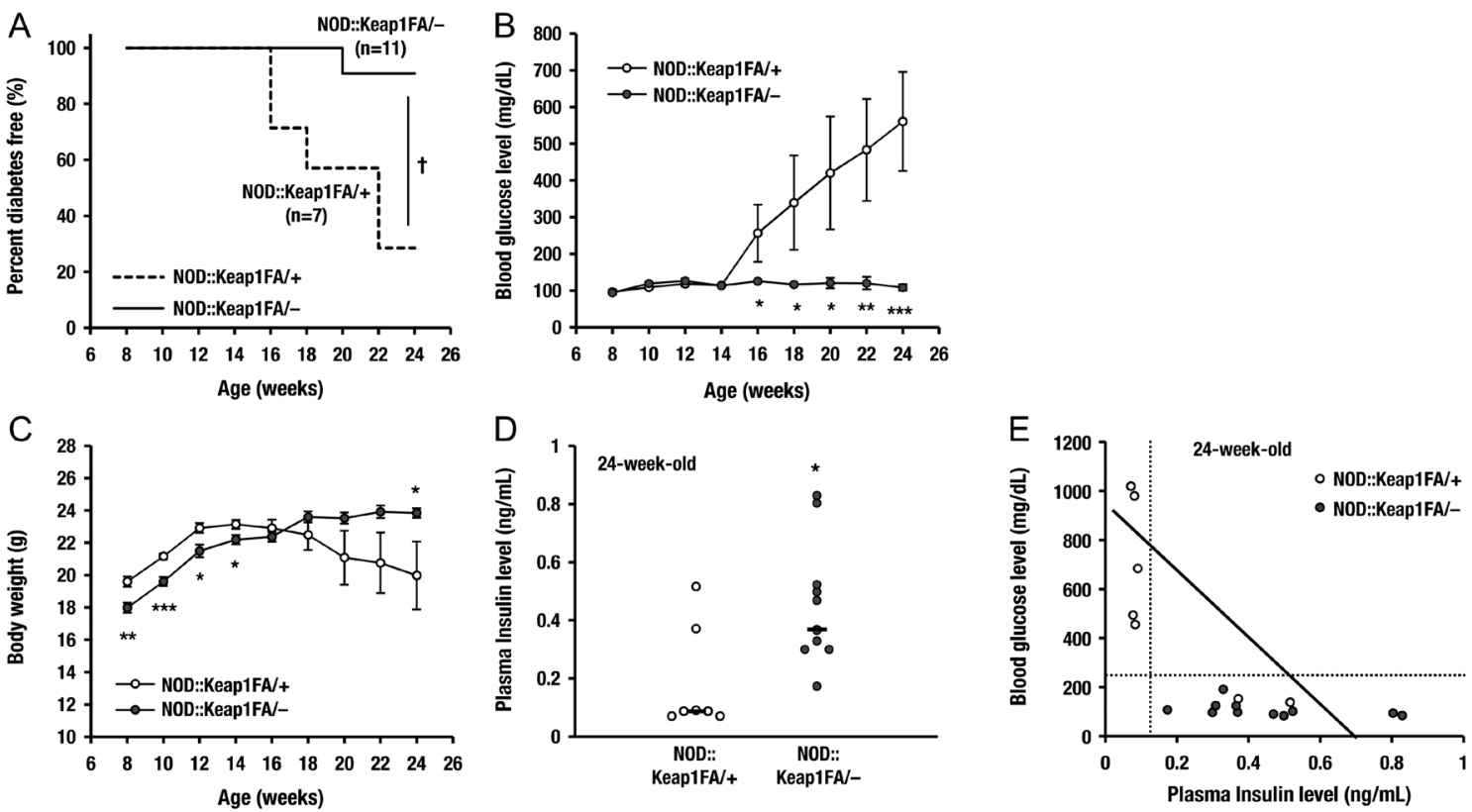

Figure 2

Activation of Nrf2 signaling decreases the incidence of diabetes in NOD mice. (A) Kaplan-Meier survival curves showing the percentages of the NOD::Keap1 FAl+ (control, $n=7$ ) and NOD::Keap 1FA- (Keap1 knockdown, $n=11$ ) mice that were diabetes-free up to 24 weeks of age. Diabetes was defined as a blood glucose level $>250 \mathrm{mg} / \mathrm{dL}$ after 2 consecutive biweekly measurements. (B and C) Changes in blood glucose levels (B) and body weights (C) in the NOD::Keap1FAl+ $(n=7)$ and NOD::Keap1FAl- $(n=11)$ mice. The data are the mean \pm S.E.M. (D) Plasma insulin levels in the NOD::Keap1FAl+ mice $(n=7)$ and NOD::Keap1FA- $(n=11)$ at 24 weeks of age. The bar represents the median. (E) Correlation between the plasma insulin levels and blood glucose levels in the NOD::Keap FAA+ $^{\text {F }}(n=7)$ and NOD::Keap 1FA- $(n=11)$ mice at 24 weeks of age. Note that high blood glucose levels (i.e., diabetic) were concentrated in the NOD::Keap $1^{\mathrm{FA} /+}$ genotype, whereas none of the NOD::Keap1FA/- mice had diabetes. Log-rank tests for the Kaplan-Meier survival curves for (A), the repeated-measures ANOVA followed by Fisher's LSD post hoc test for (B and C) and Student's $t$-test for (D) were performed. ${ }^{t} P<0.01 .{ }^{*} P<0.05$, $* \star P<0.01$ and $* * * P<0.001$ vs the NOD::Keap1FA/+ mice.

NOD::Keap1 ${ }^{\text {FA/+ }}$ mice (Fig. 2E). In addition, all the diabetic mice displayed lower plasma insulin levels than the nondiabetic mice. These data indicate that Nrf2 prevents and improves diabetes mellitus in NOD mice through protection of pancreatic $\beta$-cell function.

\section{Nrf2 activation reduces insulitis}

To investigate the reduced incidence of type 1 diabetes in genetically Nrf2-activated NOD mice, we conducted histological analyses of the pancreatic islets. In NOD mice without strong Nrf2 activation (i.e., NOD::Keap1 ${ }^{F A /+}$ mice), the significant infiltration of immune cell into the pancreatic islets was observed. At 24 weeks of age, hyperglycemic NOD::Keap $1^{\text {FA/+ }}$ mice with blood glucose levels $>400 \mathrm{mg} / \mathrm{dL}$ showed extensive inflammatory infiltration in the pancreatic islets as well as substantial islet mass reduction and islet degeneration (Fig. 3A, left panel; yellow arrowhead). Conversely, NOD::Keap1 $1^{\text {FA/+ }}$ mice with normoglycemic blood glucose levels $<150 \mathrm{mg} / \mathrm{dL}$ showed severe peri-islet accumulation of mononuclear leukocytes and less significant loss of the islet mass (Fig. 3A, middle panel).

(c) 2019 Society for Endocrinology Published by Bioscientifica Ltd. Printed in Great Britain
In contrast, no hyperglycemic NOD::Keap1 ${ }^{\text {FA/ }}$ mice were found at this age $(n=5)$. Notably, pancreatic mononuclear cell infiltration was markedly lower in the normoglycemic NOD::Keap $1^{\text {FA/- }}$ mice (Fig. 3A, right panel) than that in both the hyperglycemic and normoglycemic NOD::Keap1 ${ }^{F A /+}$ mice (left and middle panels). Indeed, the NOD::Keap $1^{\mathrm{FA} /-}$ mice had a lower percentage of islets with insulitis than the NOD::Keap $1^{F A /+}$ mice (the mean values are $32 \%$ in the NOD::Keap $1^{\text {FA/ }}$ mice vs $88 \%$ in the NOD::Keap1 ${ }^{F A /+}$ mice, Fig. 3B). We also evaluated the distribution of insulitis scores of the pancreatic islets and found that the NOD::Keap1 ${ }^{\text {FA/ }}$ mice had much less severe insulitis than the NOD::Keap $1^{\text {FA/+ }}$ mice (Fig. 3C). The total insulitis scores for individual mice were significantly lower in the NOD::Keap1 ${ }^{\text {FA/ }}$ mice than those in the NOD::Keap $1^{\text {FA/+ }}$ mice (Fig. 3D).

Immunofluorescent staining for insulin and glucagon in the pancreatic sections showed few insulin-positive cells, whereas the glucagon-positive cells were located randomly in islet areas spared from cellular infiltration in the NOD::Keap $1^{F A /+}$ mice (Fig. 4A, left and middle panels). Extensive islet infiltration of inflammatory lymphocytes and reduced insulin-positive cell numbers were especially 
A

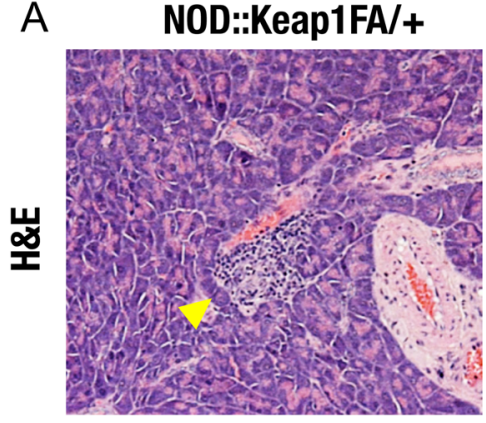

Hyperglycemic

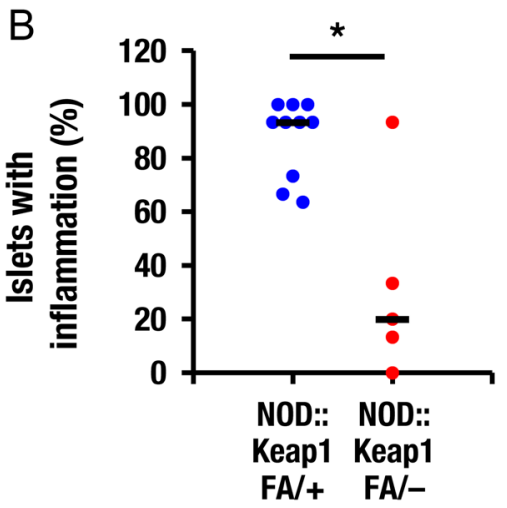

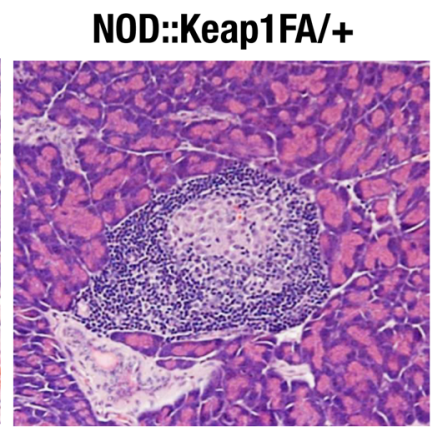

Normoglycemic

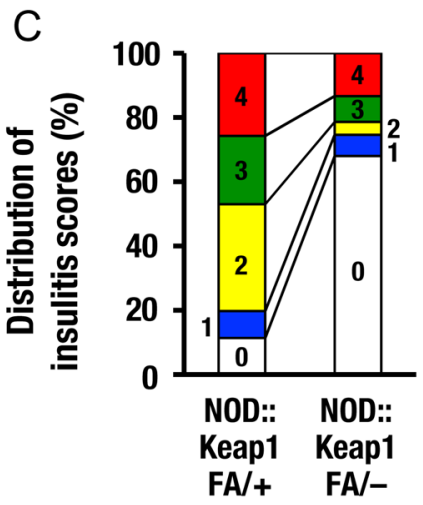

NOD::Keap1FA/-

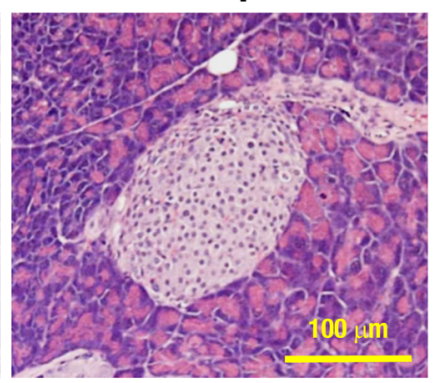

Normoglycemic

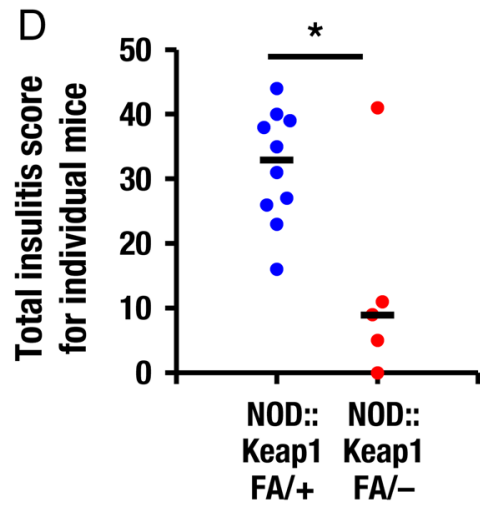

Figure 3

Activation of Nrf2 signaling prevents insulitis in NOD mice. (A) Representative images of pancreatic islets from hyperglycemic (blood glucose $>400$ mg/dL) and normoglycemic (blood glucose $<150 \mathrm{mg} / \mathrm{dL}$ ) NOD::Keap1FA/+ mice (left and middle panels, respectively) and normoglycemic NOD::Keap1FA/- mice (right panel) at 24 weeks of age. Bar, $100 \mu \mathrm{m}$. Arrowhead, extensive inflammatory cell infiltration in the islets. (B) Percentage of islets with insulitis in the NOD mice. Nine to fifteen islets of each mouse were examined for percentage of insulitis in the NOD::Keap 1FA/+ $(n=10)$ and NOD::Keap 1FA/- $(n=5)$ mice, respectively. The mean value of individual mice is shown. The bar represents the median. (C) Distribution of the insulitis scores for the NOD mice. The percentages of islets with each insulitis grade were calculated using pooled values from 70 to 130 islets from the NOD::Keap1FA/+ $(n=10)$ and NOD::Keap1FA/- $(n=5)$ mice. (D) Total insulitis scores for individual NOD mice. Nine to fifteen islets in each mouse were examined, and the 5-graded scoring scale $(0,1,2,3$ and 4) multiplied by the islet number for each grade was summed up for each individual mouse. The mean value is shown in NOD::Keap 1FA/+ $(n=10)$ and NOD::Keap1FA/- $(n=5)$ mice. The bar represents the median. Scoring scale: grade 0, no infiltration; grade 1, predominantly peri-islet mononuclear cell infiltration; grade 2, infiltration in 25-50\% of the islets; grade 3, infiltration in 50-75\% of the islets; and grade 4, infiltration in $>75 \%$ of the islets. Mann-Whitney $U$ test (B) and Student's $t$-test (D) were applied. No statistical analysis was performed in (C). * $P<0.05$.

notable in the hyperglycemic NOD::Keap $1^{F A /+}$ mice. In contrast, insulin-positive cells were detected throughout the islets and glucagon-positive cells were present in the peripheral islet areas in the NOD::Keap1 ${ }^{\text {FA/ }}$ mice (Fig. 4A, right panel).

To comprehensively assess the total mass of insulin and glucagon-positive cells in the pancreas, the insulin and glucagon contents were examined in whole pancreatic sections and pancreatic tissues in NOD::Keap $1^{\text {FA/ }}$ and NOD::Keap $1^{\text {FA/+ }}$ mice. Diabetic mice were not found in NOD::Keap $1^{\text {FA/ }}$ mice at the time of these analyses. The non-diabetic NOD::Keap $1^{F A /}$ mice showed more insulinpositive cells in whole pancreatic sections than the diabetic NOD::Keap $1^{F A /+}$ and non-diabetic NOD::Keap1 ${ }^{F A /+}$ mice (Fig. 4B). The total insulin content in the whole pancreatic tissue supported these data, with both the non-diabetic NOD::Keap1 $1^{\text {FA/ }}$ and non-diabetic NOD::Keap $1^{F A /+}$ mice showing higher insulin contents than the diabetic NOD::Keap1FA/+ mice (Fig. 4C). Although the diabetic NOD::Keap $1^{\mathrm{FA} /+}$ mice showed an increasing trend in glucagon-positive cells in the whole pancreatic sections (Fig. 4D), no significant difference was found in the total glucagon mass in the whole pancreatic sections (Fig. 4D) or the total glucagon content in the whole pancreatic tissues (Fig. 4E) among the three examined groups. Plasma glucagon levels of the diabetic NOD::Keap $1^{\text {FA/+ }}$ mice and non-diabetic NOD::Keap1 ${ }^{\text {FA/- }}$ mice were higher than those of non-diabetic NOD::Keap $1^{\text {FA/+ }}$ mice (Fig. 4F).

NQO1 immunostaining revealed significantly higher numbers of NQO1-positive cells residing in the pancreatic

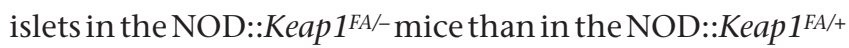
mice (Fig. 4G). These data demonstrate that the activation 


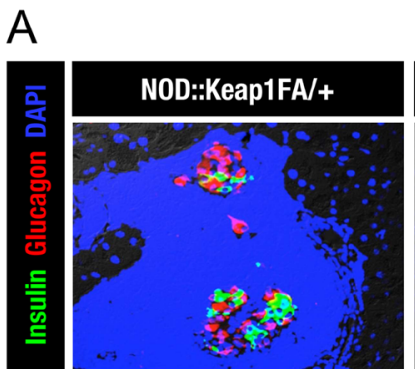

Hyperglycemic

B
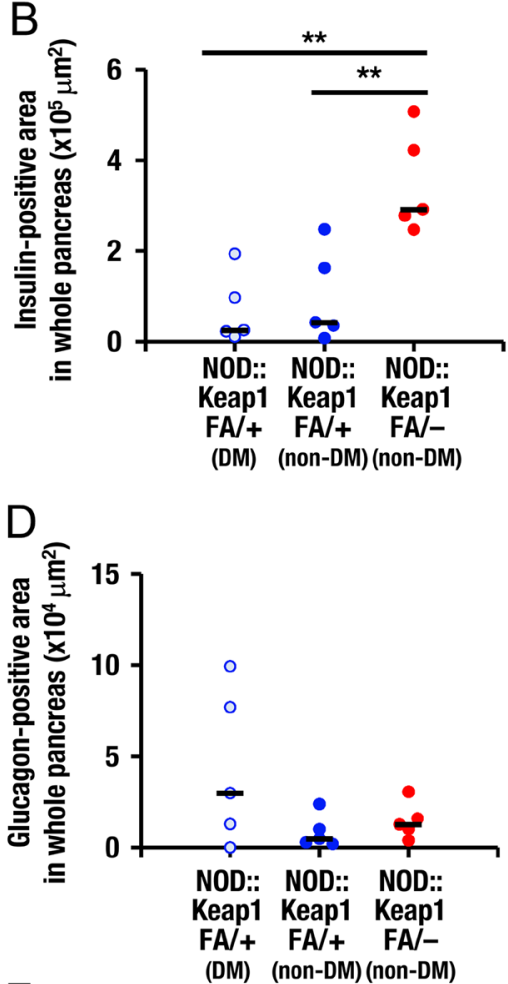

$\mathrm{F}$

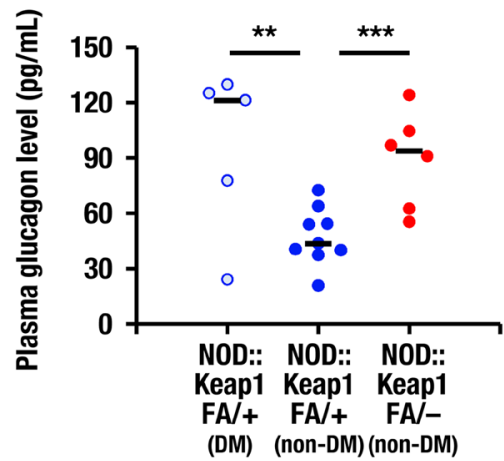

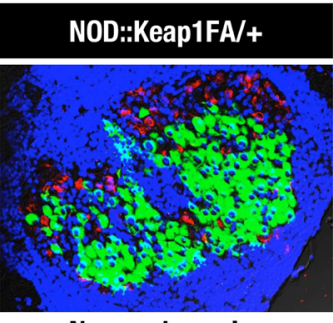

Normoglycemic

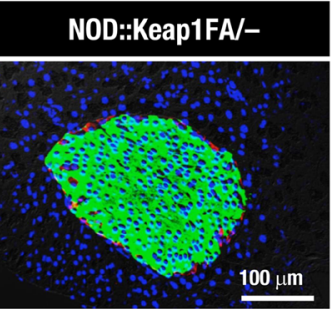

Normoglycemic

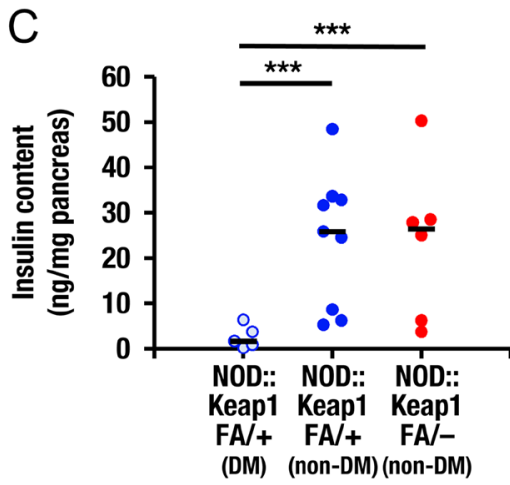

E
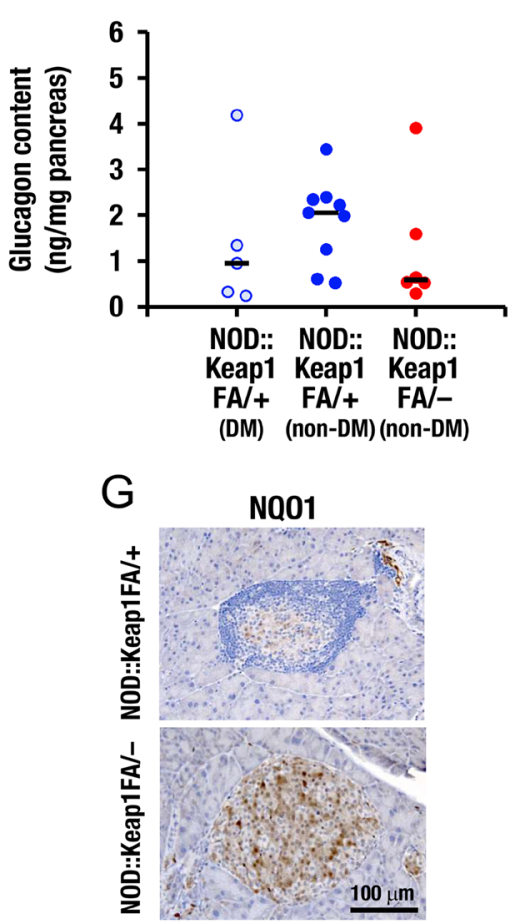

Figure 4

Activation of Nrf2 signaling protects insulin-positive cells in NOD mice. (A) Immunofluorescent staining for insulin (green) and glucagon (red) in islets from the hyperglycemic and normoglycemic NOD::Keap1FA/+ mice and the normoglycemic NOD::Keap1FA- mice at 24 weeks of age (nuclei are stained with DAPI, blue). Bar, $100 \mu \mathrm{m}$. (B and D) Insulin-positive (B) and glucagon-positive (D) areas in the whole pancreatic sections. The diabetic (DM) and non-diabetic (non-DM) NOD::Keap1FA/+ mice and the non-DM NOD::Keap1FA- ( $n=5$ in each group) mice were examined at 24 weeks of age. The bar represents the median. (C, E and F) Pancreatic insulin (C) and glucagon (E) contents and plasma glucagon levels (F) in the DM and non-DM NOD::Keap1FA/+ mice and the non-DM NOD::Keap1FAmice ( $n=5,9$ and 6, respectively) at 15 weeks of age. The bar represents the median. (G) Immunohistochemistry for NQO1 in pancreatic sections from the NOD::Keap1FA- and NOD::Keap1FA+ mice. Bar, $100 \mu \mathrm{m}$. ANOVA followed by Fisher's LSD post hoc test was applied. **P<0.01 and $* \star \star P<0.001$. 

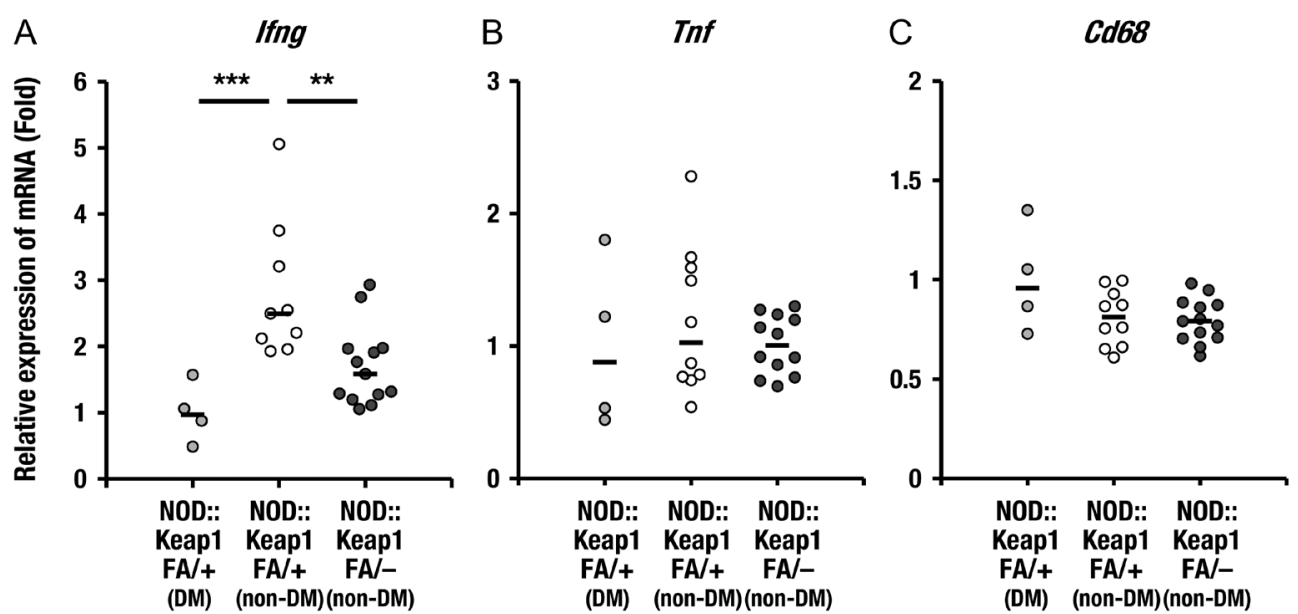

\section{Figure 5}

Inflammation-related gene expression levels in the spleens of the NOD mice. (A, B and C) mRNA expression levels of the inflammation-related genes Ifng (A), $\operatorname{Tnf}(\mathrm{B})$ and $C d 68$ (C) in the spleens of the DM and non-DM NOD::Keap1FA+ mice and the non-DM NOD::Keap1FA- mice $(n=4,10$ and 13, respectively) at 24 weeks of age. The data were normalized to Hprt for Ifng and to $\beta$-actin for Tnf and Cd68, and the expression levels in the DM NOD::Keap1FA/+ mice were set as 1. The bar represents the median. ANOVA followed by Fisher's LSD post hoc test was applied. The Grubbs' test revealed that one non-DM

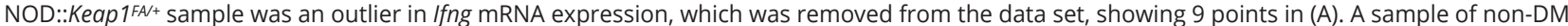
NOD::Keap1FA- did not show any signal of Tnf mRNA expression, which was removed from the data set, then 12 points were displayed in (B). $* * P<0.01$ and $* \star \star * P<0.001$

of Nrf2 signaling decreases the incidence of autoimmune diabetes in NOD mice, reflecting the tight association of inhibition of insulitis.

\section{Nrf2 and inflammation-related gene expression in the spleen}

Next, we examined whether activation of Nrf2 signaling suppressed systemic inflammation in NOD mice. To this end, we examined the expression levels of inflammationrelated genes in the spleen. The mRNA expression level of the pro-inflammatory cytokine Ifng, which encodes IFN- $\gamma$, was examined in both non-diabetic and diabetic NOD::Keap1 ${ }^{F A /+}$ mice. The Ifng mRNA levels were significantly lower in the diabetic NOD::Keap $1^{\text {FA/+ }}$ mice than those in the non-diabetic NOD::Keap1 ${ }^{F A /+}$ mice (Fig. 5A). Importantly, the Ifng expression levels were significantly lower in the non-diabetic NOD::Keap1 $1^{\text {FA/ }}$ mice than those in the non-diabetic NOD::Keap $1^{\text {FA/++ mice }}$ (Fig. 5A). Conversely, the mRNA levels of Tnf, which encodes tumor necrosis factor- $\alpha$ (TNF- $\alpha$ ), and Cd68 did not differ substantially among these three groups (Fig. 5B and C). Supplementary Figure 1 shows the correlation between the blood glucose levels and Ifng expression in the spleen based on the data shown in Fig. 5A. Although the Ifng expression level in splenic lymphocytes isolated from NOD mice was reported to correlate with diabetic progression (Yaacob et al. 2004), there was no positive correlation between the blood glucose levels and Ifng expression in the spleens of NOD::Keap $1^{\text {FA/+ }}$ mice (Supplementary Fig. 1). The diabetic NOD::Keap1 ${ }^{F A /+}$ mice showed a lower Ifng expression level than the non-diabetic NOD::Keap $1^{\text {FA/+ }}$ mice. The mechanism underlying this low Ifng expression level in the diabetic NOD::Keap1 ${ }^{\text {FA/+ }}$ mouse spleen is not clear at present. However, these data collectively showed greater depression of Ifng in the non-diabetic NOD::Keap $1^{\text {FA/- }}$ mouse spleens than in those of the non-diabetic NOD::Keap $1^{F A /+}$ mice, indicating the importance of Nrf2 activation in inhibition of Ifng expression in the spleens of NOD mice.

\section{Islet-infiltrating T-cell numbers are decreased in Nrf2-activated NOD mice}

Because the blood IFN- $\gamma$ levels correlate well with diabetes progression in NOD mice (Schloot et al. 2002) and Nrf2 suppressed Ifng mRNA expression in splenic cells from NOD mice, next we measured the plasma IFN- $\gamma$ levels in the NOD::Keap1FA/- mice. No difference in the plasma IFN- $\gamma$ concentration was found between the diabetic NOD::Keap $1^{\text {FA/++ }}$ and non-diabetic NOD::Keap $1^{\text {FA/+ }}$ mice (Fig. 6A). Notably, the clear trend for decreased plasma IFN- $\gamma$ levels was measured in the non-diabetic NOD::Keap1 ${ }^{\text {FA/- }}$ mice compared with in the diabetic NOD::Keap1 ${ }^{\mathrm{FA} /+}$ mice (Fig. 6A). This finding suggests that inflammation is systemically repressed in the NOD::Keap $1^{\text {FA- }}$ mice. 

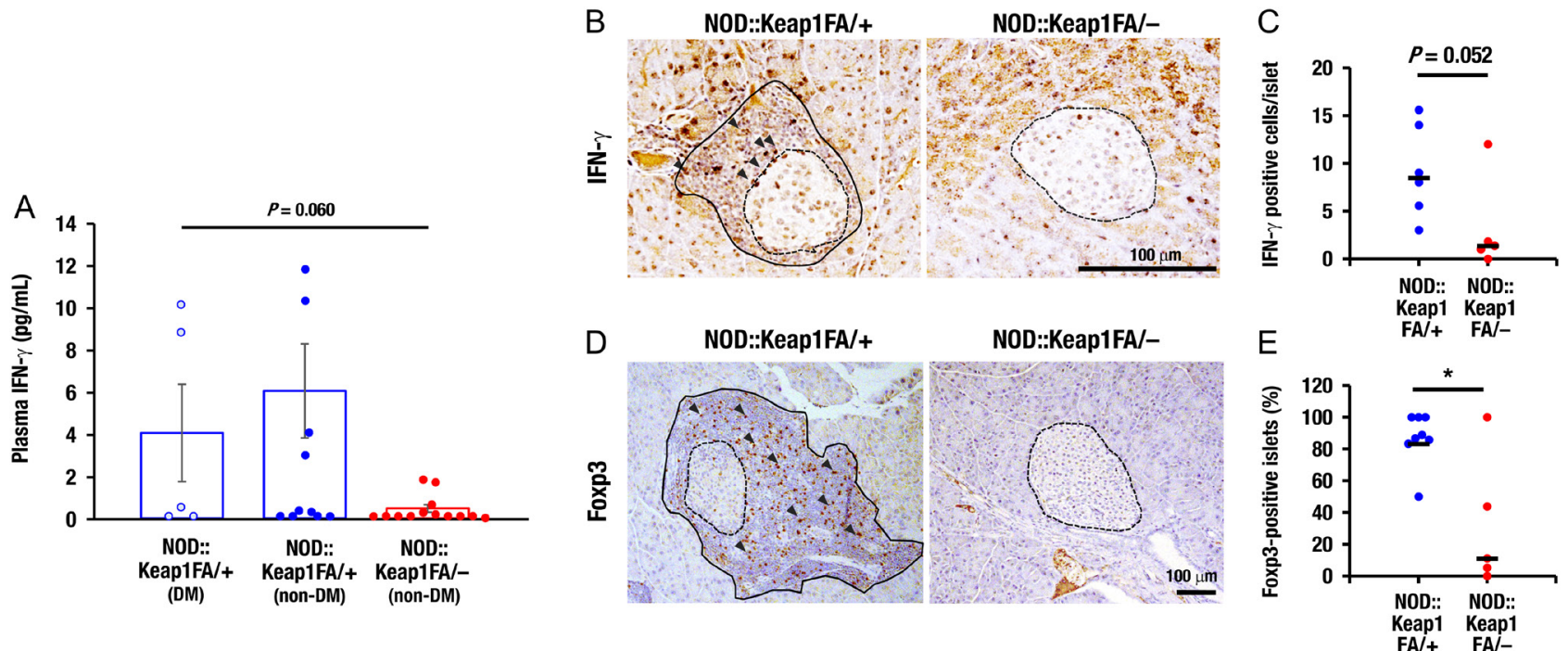

Figure 6

Islet-infiltrating T-cells in Nrf2-activated NOD mice. (A) Plasma IFN- $\gamma$ levels in the DM and non-DM NOD::Keap1FA/+ mice and the non-DM NOD::Keap1FA( $n=5,10$ and 13, respectively) mice at 24 weeks of age. The data are the mean \pm S.E.M. (B) Immunohistochemistry for IFN- $\gamma$ in pancreatic sections from the

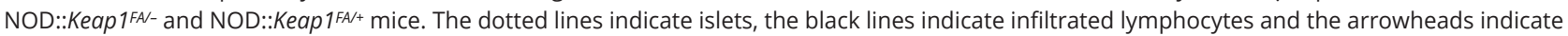
IFN- $\gamma$-positive cells. Bar, $100 \mu \mathrm{m}$. (C) Numbers of IFN- $\gamma$-positive cells per islet in the NOD mice. The individual mouse values for IFN- $\gamma$-positive cell number per islet were examined. The mean value is shown in NOD::Keap 1FA/+ $(n=6)$ and NOD::Keap1FAl- $(n=5)$ mice. The bar represents the median. (D) Immunohistochemistry for Foxp3 in pancreatic sections from the NOD::Keap 1FA/- and NOD::Keap 1FA/+ mice. The dotted lines indicate islets, the black lines indicate infiltrated lymphocytes and the arrowheads indicate Foxp3-positive cells. Bar, $100 \mu \mathrm{m}$. (E) The percentages of islets with Foxp3-positive cells in the NOD mice. The percentage of islets showing Foxp3-positive cells in the islets and surrounding areas were counted for individual mice. The mean value is shown in the NOD::Keap 1 FA/+ $(n=8)$ and NOD::Keap1 FAl- $(n=5)$ mice. The bar represents the median. ANOVA followed by Fisher's LSD post hoc test (A) and Mann-Whitney $U$ test ( $C$ and $E$ ) were applied. $* P<0.05$.

To gain insights into the inhibition of insulitis in the NOD::Keap1 ${ }^{F A /}$ mice, we examined T-cell immunity associated with pancreatic islets. During the course of development of type 1 diabetes, pro-inflammatory cytokines, including IFN- $\gamma$, have been reported to be actively produced by islet-infiltrating T-cells, and these cytokines are involved in $\beta$-cell damage (Rabinovitch et al. 1995). To investigate this issue, we counted the number of IFN- $\gamma$-positive cells located in both the islets and the surrounding tissues. Notably, the numbers of IFN- $\gamma$ positive cells in the islets and surrounding areas were lower in the NOD::Keap1 $1^{F A /-}$ mice than in the NOD::Keap $1^{\text {FA/+ }}$ mice (Fig. 6B and C).

Because regulatory T-cells (Tregs) have been reported to play a critical role in dampening insulitis by inhibiting autoreactive T-cells (McDuffie et al. 2008), we conducted Foxp3 immunostaining to clarify the immunological properties of T-cells. Foxp3 is a transcription factor that is involved in Treg development and is used as a marker for identifying Tregs (Sakaguchi et al. 2007). Foxp3 mRNA levels have been shown to increase after treatment with small molecule inducers of Nrf2 signaling (Li et al. 2013). In the NOD::Keap1 ${ }^{\text {FA/ }}$ mice, few Foxp3-positive cells were present within the islets or in the surrounding regions (Fig. 6D, right panel). In contrast, in the control NOD::Keap $1^{F A /+}$ mice with severe insulitis, Foxp3-positive T-cells resided abundantly within the islets and their surrounding regions (Fig. 6D left panel; arrowheads). Indeed, the infiltration of Foxp3-positive T-cell was frequently found in the islets of the NOD::Keap1 $1^{\text {FA/+ }}$ mice, but the frequency was significantly lower in the NOD::Keap $1^{\text {FA/ }}$ mice (Fig. 6E). These results demonstrate that infiltration of inflammatory cells, including Foxp3-positive T-cells, is significantly reduced in the NOD::Keap1 ${ }^{\text {FA/- }}$ mice.

\section{Nrf2 activation decreases the plasma $\beta$-hydroxybutyrate level in NOD mice}

To determine whether impairment of insulin secretion leads to ketosis in type 1 diabetes, we examined the plasma $\beta$-hydroxybutyrate levels in the NOD::Keap $1^{\text {FA/- }}$ mice. The NOD::Keap $1^{\text {FA/- }}$ mice had lower plasma $\beta$-hydroxybutyrate levels than the control NOD::Keap1 $1^{\text {FA/+ }}$ mice (Fig. 7A). We also examined the correlation between the plasma $\beta$-hydroxybutyrate and insulin levels. The plasma $\beta$-hydroxybutyrate levels were not significantly correlated with the plasma insulin levels in the NOD::Keap1 ${ }^{\text {FA/- }}$ or 

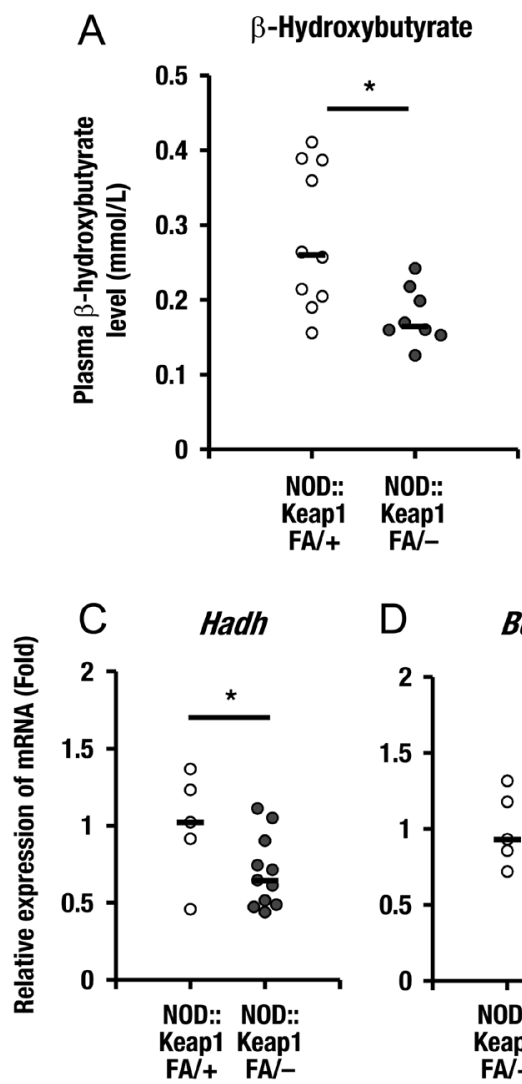
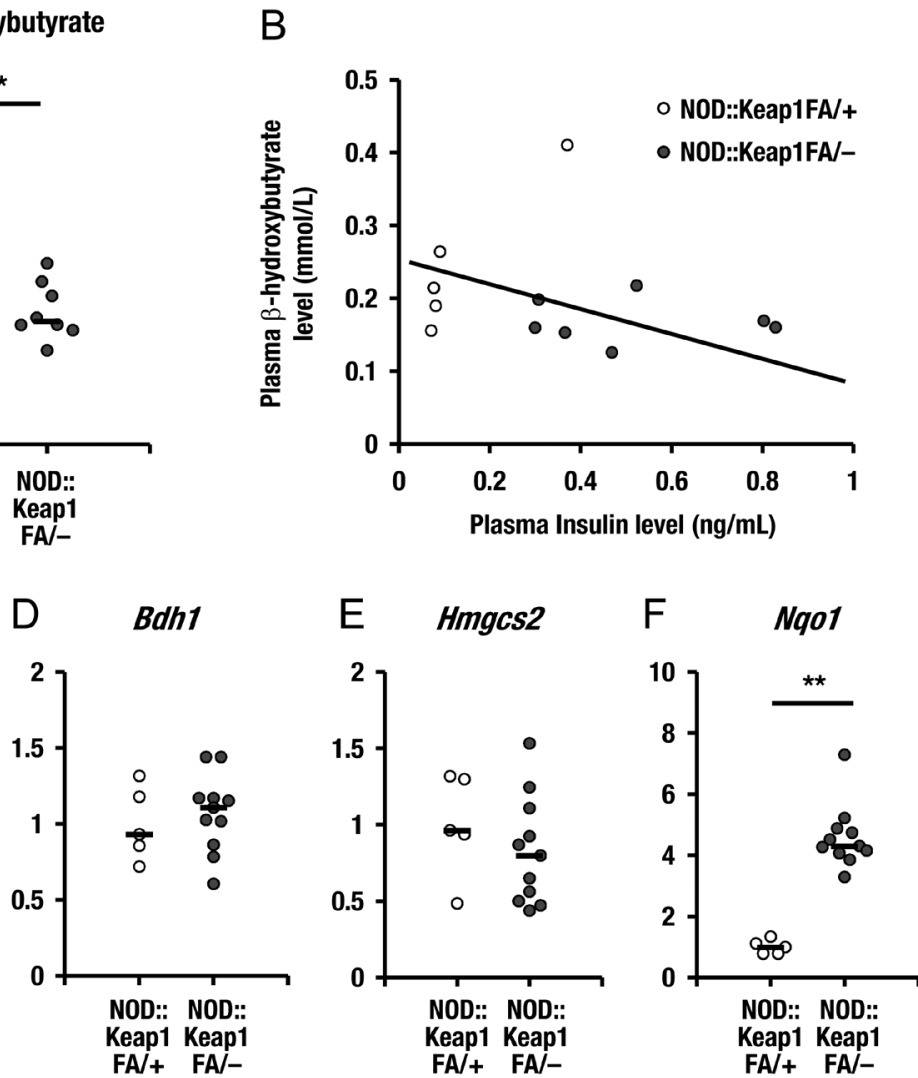

Figure 7

Activation of Nrf2 decreases the plasma $\beta$-hydroxybutyrate levels in NOD mice. (A) The plasma $\beta$-hydroxybutyrate levels in the NOD::Keap 1FA+ $(n=10)$ and NOD::Keap 1FA- $(n=8)$ mice at 24 weeks of age. The bar represents the median. (B) Correlation between the plasma insulin and $\beta$-hydroxybutyrate levels in the NOD::Keap 1FA- and NOD::Keap 1FA/+ mice at 24 weeks of age. (C, D and E) The mRNA expression levels of the $\beta$-hydroxybutyrate synthesis-related genes Hadh (C), Bdh1 (D) and Hmgcs2 (E) in the livers of the NOD::Keap1FA/+ $(n=5)$ and NOD::Keap1FA- $(n=11)$ mice at 24 weeks of age. The data were normalized to Hprt, and the expression levels in the controls were set as 1. (F) Nq01 mRNA expression levels in the livers of the NOD::Keap 1FA $(n=5)$ and NOD::Keap 1FA- $(n=11)$ mice at 24 weeks of age. The data were normalized to $\beta$-actin, and the expression level in the controls was set as 1 . The bar represents the median. Student's $t$-test was applied. $* P<0.05$ and ${ }^{*} P<0.01$.

NOD::Keap1 ${ }^{\text {FA/+ }}$ mice (Fig. 7B). These results suggest that plasma $\beta$-hydroxybutyrate is decreased in NOD::Keap $1^{F A /-}$ mice independent of the preserved insulin secretion.

Given the repression of the plasma $\beta$-hydroxybutyrate levels in the NOD::Keap1 $1^{\text {FA/ }}$ mice, the mRNA expression levels of $\beta$-hydroxybutyrate synthesis-related genes were examined in the liver. The Hadh (encodes hydroxyacylcoenzyme A dehydrogenase) expression level was significantly lower in the NOD::Keap $1^{\text {FA/ }}$ mice than in the NOD::Keap $1^{F A /+}$ mice (Fig. 7C), but the Bdh1 (encodes 3-hydroxybutyrate dehydrogenase 1) and Hmgcs2 (encodes 3-hydroxy-3-methylglutaryl-coenzyme A synthase 2) expression levels did not change substantially between the two genotypes (Fig. 7D and E). The mRNA levels of the Nrf2 target gene Nqo1 in the liver were higher in the NOD::Keap $1^{F A /-}$ mice than in the NOD::Keap $1^{F A /+}$ mice (Fig. 7F). These data support the contention that activation of Nrf2 signaling suppresses ketosis in NOD mice.

\section{An intermediate level of Nrf2 activation also suppresses diabetes in NOD mice}

Because the NOD::Keap1 $1^{\text {FAFA }}$ mice displayed lower Nrf2 activation than the NOD::Keap1 ${ }^{\text {FA/- }}$ mice (Fig. 1), we also examined the contribution of intermediate activation of Nrf2 to the suppression of type 1 diabetes using NOD::Keap $1^{\text {FAFA }}$ mice. We found that the NOD::Keap $1^{\text {FA/FA }}$ mice exhibited a significantly delayed and reduced diabetes incidence compared with that of the NOD::Keap1 ${ }^{+/+}$mice (Fig. 8A). The NOD::Keap1 $1^{\text {FA/FA }}$ mice had significantly lower blood glucose levels than the control NOD::Keap1+/+ mice (Fig. 8B). In contrast, no significant difference was observed in body weight between the genotypes (Fig. 8C). These results demonstrate that two distinct levels of Nrf2 activation in the NOD/Shi background (i.e., NOD::Keap $1^{F A /}$ and NOD::Keap1 $1^{F A / F A}$ ) reduced the incidence of type 1 diabetes. The stronger anti-diabetic 

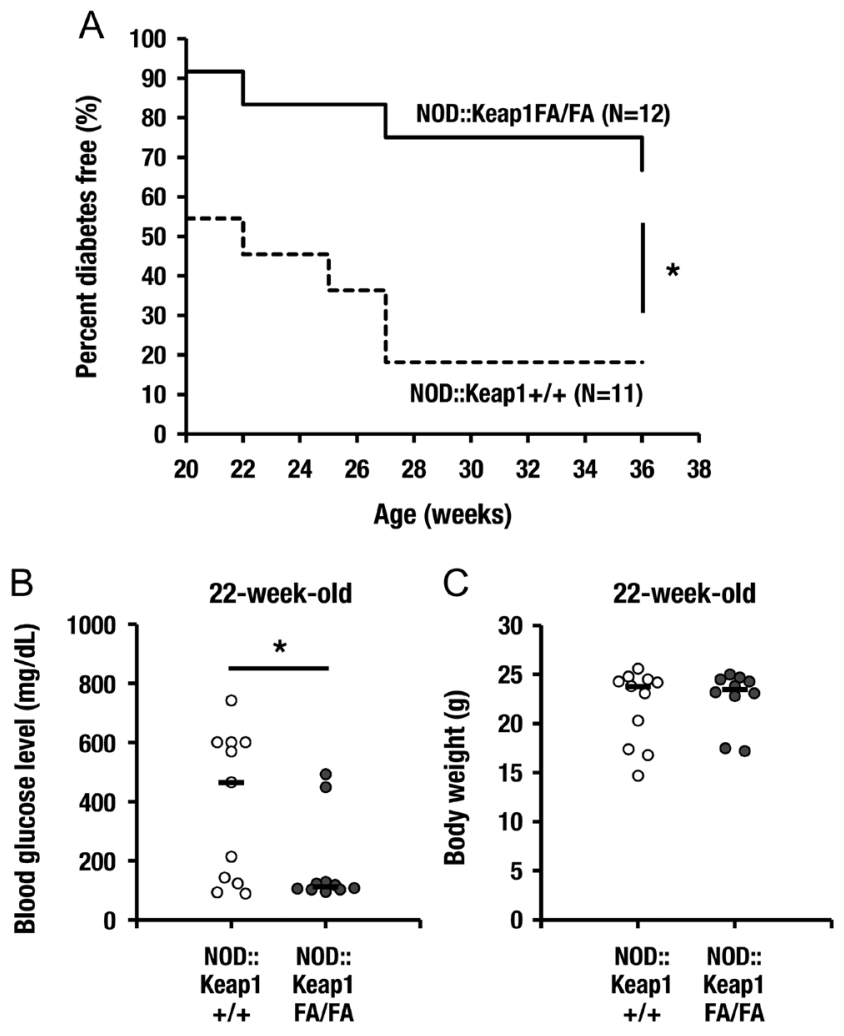

Figure 8

An intermediate level of Nrf2 activation in NOD mice also shows protection. (A) Kaplan-Meier survival curves showing the percentage of diabetes-free NOD::Keap1 1/+ $(n=11)$ and NOD::Keap1FA/FA $(n=12)$ mice. Diabetes was defined as a blood glucose level $>250 \mathrm{mg} / \mathrm{dL}$ after consecutive biweekly measurements. (B and C) Blood glucose levels (B) and body weights $(C)$ in the NOD::Keap $1^{+/+}(n=11)$ and NOD::Keap1FA/FA $(n=10)$ mice at 22 weeks of age. The bar represents the median. Log-rank tests for the Kaplan-Meier survival curves $(A)$ and Student's $t$-test ( $B$ and C) were performed. ${ }^{*} P<0.05$.

response in the NOD::Keap1 $1^{\text {FA/ }}$ mice was associated with a higher level of activation of Nrf2 signaling than that of the NOD::Keap1 ${ }^{\text {FA/FA }}$ mice.

\section{Discussion}

Nrf2 activation has been shown to contribute to antiinflammatory responses in rodent models of inflammation (Itoh et al. 2004, Khor et al. 2006, Thimmulappa et al. 2006, Lin et al. 2008, Kobayashi et al. 2016), including autoimmune inflammatory models (Wruck et al. 2011, Jiang et al. 2014). In this study, we demonstrated that genetic activation of the Nrf2 signaling pathway prevented the development and progression of type 1 autoimmune diabetes. We also showed that suppression of insulitis was the primary mechanism underlying this protective action of Nrf2 in NOD mice. Since Nrf2 upregulates a battery of anti-oxidative genes in a canonical manner, suppressing reactive oxygen species levels was considered initially to be the key molecular mechanism underlying the Nrf2mediated anti-inflammatory effects. However, recent studies have shown that Nrf2 suppresses inflammatory cytokine gene expression directly and prevents cytokine storms. In fact, we found that the Keap1-Nrf2 pathway also contributed to elimination of the inflammatory response that formed the basis for type 1 autoimmune diabetes in the NOD mouse model.

In this study, we generated two genetic models that allowed us to evaluate graded activation of the Nrf2 pathway in NOD mice. This study design enabled us to focus on assessing the roles played by Nrf2 in the development and progression of type 1 diabetes. The results clearly demonstrate that the activation of Nrf2 signaling delays the onset of type 1 diabetes and reduces the incidence of the disease in an Nrf2 gene dosage-dependent manner. Our results also demonstrate that suppression of inflammation within islets via decreasing the numbers of IFN- $\gamma$-positive T-cells may become a critical way to prevent the development of type 1 diabetes through the actions of the Nrf2 pathway. In this regard, treatment with Nrf2 inducers has been found to inhibit inflammation and modulate T-cell immunity in an experimental murine model of autoimmune encephalomyelitis (Li et al. 2013). Systemic Nrf2 activation also suppresses inflammation in autoimmune Scurfy mice (Suzuki et al. 2017). These results further support the notion that Nrf2 activation may contribute to the general amelioration of autoimmune diseases in humans.

$\beta$-cell-specific activation of the Nrf2 pathway was employed in our previous study, which found that Nrf2 effectively protected pancreatic $\beta$-cells from oxidative and nitrosative stress in an inducible nitric oxide synthase (NOS) transgenic mouse model of diabetes; these findings led us to exploit Nrf2 activation for the amelioration of metabolic outcomes (Yagishita et al. 2014). Our current data based on systemic activation of Nrf2 signaling in NOD mice indicate that activation of Nrf2 signaling indeed plays a critical role in preventing type 1 diabetes development through protecting $\beta$-cells and modulating T-cell immunity.

The glucagon content in whole pancreatic sections or pancreatic tissues did not change among the three examined groups in our study. The plasma glucagon level in the diabetic NOD::Keap $1^{\text {FA/+ }}$ mice was higher than that in the non-diabetic NOD::Keap1 ${ }^{\text {FA/ } /+}$ mice, and the non-diabetic NOD::Keap1 ${ }^{F A /}$ mice also showed higher plasma glucagon levels compared with the 
non-diabetic NOD::Keap $1^{F A /+}$ mice. These findings indicate that although glucagon plays important roles in the pathogenesis of diabetes mellitus, the protective target of Nrf2 signaling may be insulin-producing $\beta$-cells but not glucagon-producing $\alpha$-cells. The specific and augmented destruction of $\beta$-cells prior to diabetes onset induces typical insulin-deficient diabetes in NOD mice (Kikutani \& Makino 1992, Virostko et al. 2013). Activation of Nrf2 signaling strongly prevented this $\beta$-cell damage during the pre-diabetic period, which could strongly inhibit the development of diabetes in NOD mice.

We found that NOD::Keap1 ${ }^{\text {FA/ }}$ mice had lower numbers of IFN- $\gamma$-positive T-cells associated with the islets and lower levels of IFN- $\gamma$ in plasma and lower levels of Ifng mRNA expression in the spleen than the control mice. In agreement with our data, serum IFN- $\gamma$ levels are known to be correlated with diabetic progression in NOD mice (Schloot et al. 2002), and Ifng mRNA expression in the pancreatic islets is associated with insulitis and the development of type 1 diabetes (Ventura-Oliveira et al. 2002). Thus, these results suggest the presence of a critical linkage between resistance to type 1 diabetes and systemic modulation of the IFN- $\gamma$ response by Nrf 2 activation in NOD mice. We also found that the number of islets with Foxp3-positive cells was lower in the NOD::Keap1 ${ }^{\text {FA/ }}$ mice than in the control mice. Available data suggest that enhanced recruitment of Tregs may be associated with the prevention of destructive insulitis in NOD mice (Wu et al. 2002, McDuffie et al. 2008), but our data indicate that Nrf2 activation does not decrease insulitis via Treg activation. We surmise that alternative pathways may modulate autoreactive T-cells and ameliorate the IFN- $\gamma$ response through Nrf2-mediated anti-insulitis effects in the NOD model.

In Treg-deficient Scurfy mice, systemic activation of Nrf2 significantly suppresses autoimmune inflammation and alleviates effector T-cell activity and IFN- $\gamma$ production (Suzuki et al. 2017). T-cell-specific activation of Nrf2 in the same model causes attenuation of effector T-cell activity, but T-cell-specific Nrf2 activation only partially contributes to the suppression of systemic inflammation. These observations support our proposal that systemic activation of Nrf2 signaling protects against autoimmune disorders by modulating T-cell immunity and that Nrf2 signaling in various cell types should contribute to strong inhibition of the development of type 1 diabetes in the NOD background.

One salient finding of this study is that activation of Nrf2 signaling significantly decreases the plasma $\beta$-hydroxybutyrate level. NOD::Keap $1^{\text {FA/ }}$ mice showed low Hadh mRNA expression levels in the liver. However, the expression of other $\beta$-hydroxybutyrate synthesisrelated genes was not repressed by Nrf2 signaling activation. Diabetic ketoacidosis caused by ketonemia carries substantial life-threatening complications, such as cerebral edema, and this condition is the most common cause of diabetes-related death in patients. Although the mechanisms that ameliorate ketonemia remain unclear, our observations indicate a correlation between the plasma $\beta$-hydroxybutyrate levels and Nrf2 signaling in the NOD model that may suggest a potential clinical therapeutic strategy.

In conclusion, this study demonstrates that the activation of Nrf2 signaling is tightly associated with the prevention of autoimmune diabetes in NOD mice. Nrf2 activation suppresses insulitis and protects against the development and progression of autoimmune diabetes. This study indicates that optimized pharmacological strategies specifically targeting the activation of $\mathrm{Nrf} 2$ signaling in pancreatic $\beta$-cells may be useful for preventing and treating autoimmune diabetes.

\section{Supplementary data}

This is linked to the online version of the paper at https://doi.org/10.1530/ JOE-18-0355.

\section{Declaration of interest}

The authors declare that there is no conflict of interest that could be perceived as prejudicing the impartiality of the research reported.

\section{Funding}

This research is supported by the Platform Project for Supporting Drug Discovery and Life Science Research (Basis for Supporting Innovative Drug Discovery and Life Science Research (BINDS)) from the Japan Agency for Medical Research and Development (AMED) (grant number JP18am0101001 (M Y)), Grants-in-Aid for Scientific Research from the Japan Society for the Promotion of Science (JSPS) (grant numbers 24249015 (M Y), 17K01837, 16KK0195 (A U) and 26893008 (Y Y)), the National Institutes of Health (grant number R35 CA197222 (T W K)), the Takeda Foundation $(\mathrm{M} Y)$, the Naito Foundation ( $\mathrm{M} Y)$, the Japanese Foundation for Applied Enzymology (A U), the Japanese Diabetes Foundation ( $Y$ Y ) and the Shared Resource of the Fred Hutch/University of Washington Cancer Consortium (grant number P30 CA015704).

\section{Author contribution statement}

$Y Y$ and $U$ A contributed to the research data and wrote the manuscript. $\mathrm{D} \vee \mathrm{C}$ contributed to the research data and discussion. T W K and M Y contributed to the study design and manuscript preparation and are the guarantors of this work. M Y and $U \mathrm{~A}$ had full access to all of the data in the 
study and take responsibility for the integrity of the data and the accuracy of the data analysis.

\section{Acknowledgements}

The authors thank Eriko Naganuma (Tohoku University) and the Experimental Histopathology Core of Fred Hutchinson Cancer Research Center for assisting with the immunohistochemistry, the Cancer Biomarkers Facility: the Luminex Core Laboratory of the University of Pittsburgh Hillman Cancer Center for the Luminex fluorescent analyses and the Biomedical Research Core of Tohoku University Graduate School of Medicine for technical support.

\section{References}

Anderson MS \& Bluestone JA 2005 The NOD mouse: a model of immune dysregulation. Annual Review of Immunology 23 447-485. (https://doi. org/10.1146/annurev.immunol.23.021704.115643)

Axelsson AS, Tubbs E, Mecham B, Chacko S, Nenonen HA, Tang Y, Fahey JW, Derry JMJ, Wollheim CB, Wierup N, et al. 2017 Sulforaphane reduces hepatic glucose production and improves glucose control in patients with type 2 diabetes. Science Translational Medicine 9 eaah4477. (https://doi.org/10.1126/scitranslmed.aah4477)

Chartoumpekis DV \& Kensler TW 2013 New player on an old field; the keap1/Nrf2 pathway as a target for treatment of type 2 diabetes and metabolic syndrome. Current Diabetes Reviews 9 137-145. (https://doi. org/10.2174/1573399811309020005)

Cui W, Bai Y, Miao X, Luo P, Chen Q, Tan Y, Rane MJ, Miao L \& Cai L 2012 Prevention of diabetic nephropathy by sulforaphane: possible role of Nrf2 upregulation and activation. Oxidative Medicine and Cellular Longevity 2012 821936. (https://doi. org/10.1155/2012/821936)

Fox RJ, Miller DH, Phillips JT, Hutchinson M, Havrdova E, Kita M, Yang M, Raghupathi K, Novas M, Sweetser MT, et al. 2012 Placebocontrolled phase 3 study of oral BG-12 or glatiramer in multiple sclerosis. New England Journal of Medicine 367 1087-1097. (https://doi. org/10.1056/NEJMoa1206328)

Hayashi M, Takai J, Yu L, Motohashi H, Moriguchi T \& Yamamoto M 2015 Whole-body in vivo monitoring of inflammatory diseases exploiting human interleukin 6-luciferase transgenic mice. Molecular and Cellular Biology 35 3590-3601. (https://doi.org/10.1128/ MCB.00506-15)

Itoh K, Igarashi K, Hayashi N, Nishizawa M \& Yamamoto M 1995 Cloning and characterization of a novel erythroid cell-derived CNC family transcription factor heterodimerizing with the small Maf family proteins. Molecular and Cellular Biology 15 4184-4193. (https://doi. org/10.1128/MCB.15.8.4184)

Itoh K, Chiba T, Takahashi S, Ishii T, Igarashi K, Katoh Y, Oyake T, Hayashi N, Satoh K, Hatayama I, et al. 1997 An Nrf2/small Maf heterodimer mediates the induction of phase II detoxifying enzyme genes through antioxidant response elements. Biochemical and Biophysical Research Communications 236 313-322. (https://doi. org/10.1006/bbrc.1997.6943)

Itoh K, Wakabayashi N, Katoh Y, Ishii T, Igarashi K, Engel JD \& Yamamoto M 1999 Keap1 represses nuclear activation of antioxidant responsive elements by Nrf2 through binding to the amino-terminal Neh2 domain. Genes and Development 13 76-86. (https://doi. org/10.1101/gad.13.1.76)

Itoh K, Mochizuki M, Ishii Y, Ishii T, Shibata T, Kawamoto Y, Kelly V, Sekizawa K, Uchida K \& Yamamoto M 2004 Transcription factor Nrf2 regulates inflammation by mediating the effect of 15-deoxyDelta(12,14)-prostaglandin J(2). Molecular and Cellular Biology 24 36-45. (https://doi.org/10.1128/MCB.24.1.36-45.2004)
Jiang T, Tian F, Zheng H, Whitman SA, Lin Y, Zhang Z, Zhang N \& Zhang DD 2014 Nrf2 suppresses lupus nephritis through inhibition of oxidative injury and the NF-kappaB-mediated inflammatory response. Kidney International 85 333-343. (https://doi.org/10.1038/ ki.2013.343)

Kaplan EL \& Meier P 1958 Nonparametric estimation from incomplete observations. Journal of the American Statistical Association 53 457-481. (https://doi.org/10.1080/01621459.1958.10501452)

Kensler TW, Wakabayashi N \& Biswal S 2007 Cell survival responses to environmental stresses via the Keap1-Nrf2-ARE pathway. Annual Review of Pharmacology and Toxicology 47 89-116. (https://doi. org/10.1146/annurev.pharmtox.46.120604.141046)

Khor TO, Huang M-T, Kwon KH, Chan JY, Reddy BS \& Kong A-N 2006 Nrf2-deficient mice have an increased susceptibility to dextran sulfate sodium-induced colitis. Cancer Research 66 11580-11584. (https://doi. org/10.1158/0008-5472.CAN-06-3562)

Kikutani H \& Makino S 1992 The murine autoimmune diabetes model: NOD and related strains. Advances in Immunology 51 285-322. (https://doi.org/10.1016/S0065-2776(08)60490-3)

Kobayashi EH, Suzuki T, Funayama R, Nagashima T, Hayashi M, Sekine H, Tanaka N, Moriguchi T, Motohashi H, Nakayama K, et al. 2016 Nrf2 suppresses macrophage inflammatory response by blocking proinflammatory cytokine transcription. Nature Communications $\mathbf{7}$ 11624. (https://doi.org/10.1038/ncomms11624)

Li B, Cui W, Liu J, Li R, Liu Q, Xie XH, Ge XL, Zhang J, Song XJ, Wang Y, et al. 2013 Sulforaphane ameliorates the development of experimental autoimmune encephalomyelitis by antagonizing oxidative stress and Th17-related inflammation in mice. Experimental Neurology 250 239-249. (https://doi.org/10.1016/j.expneurol.2013.10.002)

Lin W, Wu RT, Wu T, Khor TO, Wang H \& Kong A 2008 Sulforaphane suppressed LPS-induced inflammation in mouse peritoneal macrophages through Nrf2 dependent pathway. Biochemical Pharmacology 76 967-973. (https://doi.org/10.1016/j.bcp.2008.07.036)

Makino S, Kunimoto K, Muraoka Y, Mizushima Y, Katagiri K \& Tochino Y 1980 Breeding of a non-obese, diabetic strain of mice. Jikken Dobutsu 29 1-13. (https://doi.org/10.1538/expanim1978.29.1_1)

McDuffie M, Maybee NA, Keller SR, Stevens BK, Garmey JC, Morris MA, Kropf E, Rival C, Ma K, Carter JD, et al. 2008 Nonobese diabetic (NOD) mice congenic for a targeted deletion of 12/15-lipoxygenase are protected from autoimmune diabetes. Diabetes 57 199-208. (https://doi.org/10.2337/db07-0830)

Okawa H, Motohashi H, Kobayashi A, Aburatani H, Kensler TW \& Yamamoto M 2006 Hepatocyte-specific deletion of the keap1 gene activates Nrf2 and confers potent resistance against acute drug toxicity. Biochemical and Biophysical Research Communications 339 79-88. (https://doi.org/10.1016/j.bbrc.2005.10.185)

Rabinovitch A, Suarez-Pinzon WL, Sorensen O, Bleackley RC \& Power RF 1995 IFN-gamma gene expression in pancreatic islet-infiltrating mononuclear cells correlates with autoimmune diabetes in nonobese diabetic mice. Journal of Immunology 154 4874-4882.

Sakaguchi S, Wing K \& Miyara M 2007 Regulatory T cells - a brief history and perspective. European Journal of Immunology 37 (Supplement 1) S116-S123. (https://doi.org/10.1002/eji.200737593)

Schloot NC, Hanifi-Moghaddam P, Goebel C, Shatavi SV, Flohe S, Kolb H \& Rothe H 2002 Serum IFN-gamma and IL-10 levels are associated with disease progression in non-obese diabetic mice. Diabetes/ Metabolism Research and Reviews 18 64-70. (https://doi.org/10.1002/ dmrr.256)

Slocum SL, Skoko JJ, Wakabayashi N, Aja S, Yamamoto M, Kensler TW \& Chartoumpekis DV 2016 Keap1/Nrf2 pathway activation leads to a repressed hepatic gluconeogenic and lipogenic program in mice on a high-fat diet. Archives of Biochemistry and Biophysics 591 57-65. (https://doi.org/10.1016/j.abb.2015.11.040)

Song MY, Kim EK, Moon WS, Park JW, Kim HJ, So HS, Park R, Kwon KB \& Park BH 2009 Sulforaphane protects against cytokine- and streptozotocin-induced beta-cell damage by suppressing the 
NF-kappaB pathway. Toxicology and Applied Pharmacology 235 57-67. (https://doi.org/10.1016/j.taap.2008.11.007)

Suzuki T, Murakami S, Biswal SS, Sakaguchi S, Harigae H, Yamamoto M \& Motohashi H 2017 Systemic activation of NRF2 alleviates lethal autoimmune inflammation in scurfy mice. Molecular and Cellular Biology 37. (https://doi.org/10.1128/MCB.00063-17)

Taguchi K, Maher JM, Suzuki T, Kawatani Y, Motohashi H \& Yamamoto M 2010 Genetic analysis of cytoprotective functions supported by graded expression of Keap1. Molecular and Cellular Biology 30 3016-3026. (https://doi.org/10.1128/MCB.01591-09)

Taguchi K, Motohashi H \& Yamamoto M 2011 Molecular mechanisms of the Keap1-Nrf2 pathway in stress response and cancer evolution. Genes to Cells 16 123-140. (https://doi.org/10.1111/j.13652443.2010.01473.x)

Thimmulappa RK, Scollick C, Traore K, Yates M, Trush MA, Liby KT, Sporn MB, Yamamoto M, Kensler TW \& Biswal S 2006 Nrf2dependent protection from LPS induced inflammatory response and mortality by CDDO-Imidazolide. Biochemical and Biophysical Research Communications 351 883-889. (https://doi.org/10.1016/j. bbrc.2006.10.102)

Tuomilehto J 2013 The emerging global epidemic of type 1 diabetes. Current Diabetes Reports 13 795-804. (https://doi.org/10.1007/s11892013-0433-5)

Uruno A \& Motohashi H 2011 The Keap1-Nrf2 system as an in vivo sensor for electrophiles. Nitric Oxide 25 153-160. (https://doi org/10.1016/j.niox.2011.02.007)

Uruno A, Furusawa Y, Yagishita Y, Fukutomi T, Muramatsu H, Negishi T, Sugawara A, Kensler TW \& Yamamoto M 2013 The Keap1-Nrf2 system prevents onset of diabetes mellitus. Molecular and Cellular Biology 33 2996-3010. (https://doi.org/10.1128/МСВ.00225-13)

Uruno A, Yagishita Y \& Yamamoto M 2015 The Keap1-Nrf2 system and diabetes mellitus. Archives of Biochemistry and Biophysics 566 76-84. (https://doi.org/10.1016/j.abb.2014.12.012)

Uruno A, Yagishita Y, Katsuoka F, Kitajima Y, Nunomiya A, Nagatomi R, Pi J, Biswal SS \& Yamamoto M 2016 Nrf2-mediated regulation of skeletal muscle glycogen metabolism. Molecular and Cellular Biology 36 1655-1672. (https://doi.org/10.1128/MCB.01095-15)

Van Belle TL, Taylor P \& von Herrath MG 2009 Mouse models for Type 1 diabetes. Drug Discovery Today: Disease Models 6 41-45. (https://doi. org/10.1016/j.ddmod.2009.03.008)

Ventura-Oliveira D, Vilella CA, Zanin ME, Castro GM, Moreira Filho DC \& Zollner RL 2002 Kinetics of TNF-alpha and IFN-gamma mRNA expression in islets and spleen of NOD mice. Brazilian Journal of Medical and Biological Research 35 1347-1355. (https://doi. org/10.1590/S0100-879X2002001100013)

Virostko J, Radhika A, Poffenberger G, Dula AN, Moore DJ \& Powers AC 2013 Bioluminescence imaging reveals dynamics of beta cell loss in the non-obese diabetic (NOD) mouse model. PLOS ONE 8 e 57784. (https://doi.org/10.1371/journal.pone.0057784)

Wakabayashi N, Itoh K, Wakabayashi J, Motohashi H, Noda S, Takahashi S, Imakado S, Kotsuji T, Otsuka F, Roop DR, et al. 2003 Keap1-null mutation leads to postnatal lethality due to constitutive Nrf2 activation. Nature Genetics 35 238-245. (https://doi.org/10.1038/ng1248)

Wruck CJ, Fragoulis A, Gurzynski A, Brandenburg L-O, Kan YW, Chan K, Hassenpflug J, Freitag-Wolf S, Varoga D, Lippross S, et al. 2011 Role of oxidative stress in rheumatoid arthritis: insights from the Nrf2knockout mice. Annals of the Rheumatic Diseases 70 844-850. (https:// doi.org/10.1136/ard.2010.132720)

Wu AJ, Hua H, Munson SH \& McDevitt HO 2002 Tumor necrosis factoralpha regulation of CD4+CD25+ T cell levels in NOD mice. PNAS 99 12287-12292. (https://doi.org/10.1073/pnas.172382999)

Yaacob NS, Kaderi MA \& Norazmi MN 2004 The expression of cytokine genes in the peritoneal macrophages and splenic CD4- and CD8positive lymphocytes of the nonobese diabetic mice. Journal of Clinical Immunology 24 177-184. (https://doi.org/10.1023/ B:JOCI.0000019783.61674.1d)

Yagishita Y, Fukutomi T, Sugawara A, Kawamura H, Takahashi T, Pi J, Uruno A \& Yamamoto M 2014 Nrf2 protects pancreatic beta-cells from oxidative and nitrosative stress in diabetic model mice. Diabetes 63 605-618. (https://doi.org/10.2337/db13-0909)

Yagishita Y, Uruno A, Fukutomi T, Saito R, Saigusa D, Pi J, Fukamizu A, Sugiyama F, Takahashi S \& Yamamoto M 2017 Nrf2 improves leptin and insulin resistance provoked by hypothalamic oxidative stress. Cell Reports 18 2030-2044. (https://doi.org/10.1016/j.celrep.2017.01.064)

Yamamoto M, Kensler TW \& Motohashi H 2018 The Keap1-Nrf2 system: a thiol-based sensor-effector apparatus for maintaining redox homeostasis. Physiological Reviews 98 1169-1203. (https://doi. org/10.1152/physrev.00023.2017)

Zhang YJ, Yeager RL, Tanaka Y \& Klaassen CD 2010 Enhanced expression of Nrf2 in mice attenuates the fatty liver produced by a methionineand choline-deficient diet. Toxicology and Applied Pharmacology $\mathbf{2 4 5}$ 326-334. (https://doi.org/10.1016/j.taap.2010.03.016)

Zheng H, Whitman SA, Wu W, Wondrak GT, Wong PK, Fang D \& Zhang DD 2011 Therapeutic potential of Nrf2 activators in streptozotocin-induced diabetic nephropathy. Diabetes 60 3055-3066. (https://doi.org/10.2337/db11-0807)

Received in final form 16 December 2018

Accepted 24 December 2018

Accepted Preprint published online 2 January 2019 https://joe.bioscientifica.com https://doi.org/10.1530/JOE-18-0355 (c) 2019 Society for Endocrinology Published by Bioscientifica Ltd. Printed in Great Britain 